\title{
A new middle Miocene crocidosoricine shrew from the Mongolian Shargain Gobi Desert
}

Vladimir S. Zazhigin and Leonid L. Voyta

Acta Palaeontologica Polonica 63 (1), 2018: 171-187 doi:https://doi.org/10.4202/app.00396.2017

The crocidosoricines are a relatively widespread subfamily of shrews with an early

Oligocene to late Miocene temporal range, generally known from Europe, and, to a lesser extent, from Asia. A new discovery from the Mongolian middle Miocene locality Sharga 2 (the lower part of the Oshin Suite) added new data to the understanding of Crocidosoricinae arising in Asia, and allowed the description of a new genus and species: Shargainosorex angustirostris gen. et sp. nov. A large number of the fossil remains (more than 200 specimens from 95-100 buried shrews) made it possible to make a detailed description of the morphology of the new species, and even to try to reconstruct the rostrum shape and estimate the size of the skull and body. Morphologically, and apparently adaptively, the Shargain shrew was more similar to the Sorex species, including tooth pigmentation, but also carried a number of white-toothed shrew features (Crocidura, Suncus). Based on these findings, we can assume the spreading of Miosorex sensu lato. from Europe to Asia during the early Miocene, when the group acquired a number of adaptive sorex-like features as a possible result of occupying new trophic niches in this part of the continent.

Key words: Mammalia, Soricidae, Crocidosoricinae, Miosorex, Neogene, Miocene, Shargain Gobi, Mongolia.

Vladimir S. Zazhigin [zazhvol@gmail.com], Geological Institute, Russian Academy of Sciences, Pyzhevskii per. 7, Moscow, 109017, Russia. Leonid L.

Voyta [Leonid.Voyta@zin.ru] (corresponding author), Laboratory of Theriology, Zoological Institute, Russian Academy of Sciences, Universitetskaya nab. 1, Saint Petersburg, 199034, Russia.

This is an open-access article distributed under the terms of the Creative Commons Attribution License (for details please see creativecommons.org), which permits unrestricted use, distribution, and reproduction in any medium, provided the original author and source are credited. 
FaF Full text $(947.0 \mathrm{kB})$ ।

Far 5 Supplementary file $(720.9 \mathrm{kB})$ 